\title{
Media Violence Reports on the Cameroon Anglophone Crisis: Implication on Buea Denizens
}

\author{
Kingsley Lyonga Ngange ${ }^{1 *}$, Nengieh Lizzie Wantchami ${ }^{2}$, Mesumbe Neville Ndiwang ${ }^{3}$, Mewoabi \\ Temateh Stephenia ${ }^{3}$ \\ ${ }^{1}$ Head of Department Department of Journalism and Mass Communication, University of Buea, Cameroon \\ ${ }^{2}$ Lecturer Department of Journalism and Mass Communication, Department of Educational Foundations and \\ Administration, University of Buea, Cameroon \\ ${ }^{3}$ Graduate student Department of Journalism and Mass Communication, University of Buea
}

*Corresponding Author: Kingsley Lyonga Ngange, Head of Department Department of Journalism and Mass Communication, University of Buea, Cameroon

\begin{abstract}
Media play a significant role in conflict resolution. Media reports can resort to either peaceful resolutions or flare up conflicts. This study seeks to examine the attitude of Buea inhabitants after consuming violent reports on the Cameroon Anglophone crisis. Cross sectional survey design was adopted for this study. The researchers made used of purposive sampling to collect data from 100 Molyko dwellers. Findings indicate that the dwellers have different interpretations of reality after consuming violent contents through multimedia. While 66 (68.8\%) respondents think Cameroon in particular and the world in general, are full of violence, 27 (28.1\%) of respondents do not think same. Also, $38(39.6 \%)$ respondents were of the opinion that violent contents cause them to be reserved and cautions. Others, become scared, develop hatred for separatists and government as well as the feeling to join the armed struggle. This study therefore concludes that the power of the media should not be neglected especially during crisis periods and governments as well as media practitioners and other conflict stakeholders should be cautious of the effects of media messages on their audiences in creating, escalating and promoting crisis situations
\end{abstract}

Keywords: Cameroon Anglophone Crisis, Media violence Reports, Media effects, Buea

\section{INTRODUCTION}

Media reports during crisis periods have been known to resort to either peaceful resolutions or flare up conflicts. Exposure to violence reports however, instigates psychological discomforts which spring either negative, positive, or lukewarm encounters depending on audience exposure or experience during crisis situations. Researchers have reported that exposure to violent media content escalated aggressive cognition, aggressive effect, physiological arousal, aggressive behaviour, and decreased pro-social behaviour (Zeng, Dai, Tang, \& Zhang, 2004; Anderson \& Bushman, 2001; Huesmann, Moise-Titus, Podolski, \& Eron, 2003). However, most of the studies done on media violence, focus on violent movies and violent video games (Zhang, Xiong \& Tian, 2013; Anderson \& Dill, 2000, Bushman \& Anderson, 2002, Ballard \& Lineberger 1999). This study goes beyond violent movies and violent videos games, to look at the implications of violence reports during crisis. Also, most studies examining whether exposure to violent behaviour on film or television tends to increase aggressive behaviour in the short term (Bushman \& Huesmann, 2001; Comstock, 1980; Geen, 1990; Geen \& Thomas, 1986; Huesmann, Moise, \& Podolski, 1997) have used laboratory and field experiments. But, this study makes use of a cross sectional survey. The consistent result from such randomised experiments is that youths who watch violent scenes subsequently display more aggressive behaviour, aggressive thoughts, and/or aggressive emotions than those who do not. Similarly, some of the cross sectional survey researches provide convincing evidence that frequent viewing of violence in the media is associated with comparatively high levels of aggressive behaviour (Paik \& Comstock, 1994; Chaffee, 1972; Comstock, 1980; Eysenck \& Nias, 1978; Huesmann \& Miller, 1994). However, these cross-sectional surveys alone do not indicate whether media violence causes aggression, whether aggressive youth are attracted to media violence, or whether some other factor predisposes the same 
youth to watch more violence and behave more aggressively than their peers, (Anderson, Berkowitz, Donnerstein, Huesmann, Johnson, Linz, Malamuth, Wartella, 2003). This study considers the ongoing Cameroon Anglophone Crisis, which started with the lawyers and teachers strikes in 2016, as a prime factor which predisposes youth to be exposed to media violence.

Aggression is defined by psychologists as any behaviour that is intended to harm another person. There are many forms of aggression. For example, verbal aggression usually refers to saying hurtful things to the victim. Relational or indirect aggression refers to behaviour that is intended to harm the target person but is enacted outside of the target person's view (behind his or her back), such as telling lies to get the person in trouble or to harm his or her interpersonal relationships. The aggressive behaviours of greatest concern usually involve physical aggression. Physical aggression may range in severity from less serious acts, such as pushing or shoving, to more serious physical assaults and fighting, extending to violent acts that carry a significant risk of serious injury (Anderson et al., 2003). Anderson et al. (2003) note further that violent actions seldom result from a single cause; rather, multiple factors converging over time contribute to such behaviour. This is eminent with the Anglophone crisis in Cameroon which can be traced back to 1961, when the political elites of two territories with different colonial legacies, (French and British) agreed on the formation of a federal state. Contrary to expectations, this did not provide for equal partnership of both parties, let alone the preservation of cultural heritage and identity of each other (Konings \& Nyamnjoh 1997). Hence, there have been criticisms which have fuelled anger and desperation from one party (British) as noted by Tchoyi (2017) over a centralised state; transfer of decision-making centres to Yaoundé (the political capital), far from the Anglophone population and their problems as well as failure to respect commitments to equitably take into account the institutional, legal and administrative cultures and traditions inherited from the former colonial powers. There has also been grievances relating to the non-compliance to the solemn promises made during the referendum campaigns (referring to 1961 plebiscite and 1972 referendum); the change of the name of the State, from the "United Republic of Cameroon" to the "Republic of Cameroon" and disrespect of bilingualism in the public sector, although the Constitution makes French and English two official languages of equal status (Okereke, 2018). The conflict between Anglophone and Francophone Cameroonians took a lethal turn in 2016 when widespread peaceful protests and strikes from lawyers and teachers emerged. Media reports focused on the role of common law lawyers advocating to abandon the Cameroon Bar Association. Other groups, including the country's teachers, then joined the protests on $21^{\text {st }}$ November 2016. The protests turned violent and in late November, cases of sexual violence against students in the University of Buea were reported (Tala \& Ngange, 2019).

Many studies have examined the immediate effect of media violence on aggressive thoughts or emotions (Berkowitz, 1993; Bushman \& Huesmann, 2001; Geen, 2001; Rule \& Ferguson, 1986). These studies deserve attention because research has shown that the risk of physically aggressive behaviour against other people is increasing among youth who believe that violence against others is acceptable (Huesmann \& Guerra, 1997), in part because they believe that their targets are "bad" people and that punishing them is justified (Berkowitz, 1965; Berkowitz \& Geen, 1967). In view of the Cameroon Anglophone Crisis, there have been tremendous violence reports after the deployment of security forces to the North West and South West regions to crackdown separatist elements, as guerrilla attacks from these separatists/secessionists within the self-declared "Ambazonian Defence Forces" (ADF) has lead to the abduction and killing of over 5000 civilians and Cameroon security personnel, as well as the displacement of over 200,000 people (Crisis Group Africa Briefing $\mathrm{N}^{\circ} 130$, 2017; Okereke, 2018).

Anderson et al. (2003) further assert that media violence may lead to aggressive emotions that lead to anger, a consequence to aggressive behaviour. According to Cedric (1984), most of the research on television violence is designed to demonstrate a clear connection between what is seen on the screen and what is enacted in real life. As one researcher noted, "the news media, rather than personal experience provide Americans with their predominate fears" (Glassner, xxi 1999). George Gerbner found that people who watch a lot of television are more likely than others to believe their neighbourhoods are unsafe, to assume that crime rates are rising, and to overestimate their own odds of becoming a victim (Glassner, 1999).

Florea (2013) says violence has so far been an indispensable part of our lives as children or adults. It does not matter if we are children or adults, we might be the "aggressors, victims or witnesses of an aggression" (p. 350). Indeed as a consequence of political, economic or social reasons, in today's 
world any incident might easily trigger deep-rooted aggression. This assertion is eminent in the reported violent behaviour of Cameroonian youth as violence has dominated the Cameroon media landscape since the beginning of the Anglophone crisis in 2016. Video recordings of violence are glaring over social media platforms, local television stations as well as in newspapers reports. Media such as The Post, The Guardian Post, Equinox Radio and Television, Bareta Online News and Southern Cameroons Broadcasting Corporation (SCBC) report issues on houses razed, torture and inhuman treatment, arbitrary arrest, sexual abuse, kidnap as well as mutilation of civilians, separatists and military body parts. This has had some negative effects on the audience. The reports arouse emotions which have propelled some individuals to either join or identify with the separatists or the military, depending on their ideological/cultural leanings. The Southern Cameroons Broadcasting Corporation (SCBC) was banned from airing in Cameroon for its pro-Anglophone separatists leaning (African Media Barometer: Cameroon, 2018). Cable and satellite television distributors were arrested and detained in parts of the North West region for including the channel in their TV bundles (African Media Barometer: Cameroon, ibid). Also, security forces ransacked homes and destroyed the TV sets of citizens suspected to be watching SCBC (http://scbc.com.tag.crisis).

The effect of the consistent media report on violence can better be explained using the mean world syndrome (Lekeaka, 2017). Viewing violence can increase the fear of becoming a victim and a sense of mistrust of others. Research by George Gebner and his colleagues (1980) has shown that heavy viewers tend to see the world as dangerous and are more fearful of walking alone in their own neighbourhood. This is common among youth. This is known as "mean world syndrome". Media consumers may become so overwhelmed by negative portrayals of crime and violence that they may begin either cynically or despondently to believe the real world is a mean and harsh place (Gerbner, Gross, Jackson-Beeck, Jeffries-Fox, \& Signorielli, 1978; Wilkinson \& Fletcher, 1995). The more a person watches television, the more suspicious a person is and the greater the person's expectancy of being involved in real violence (Lefkowits \& Huesmann, 1980). Also, aggressive cues theorists are quick to point out that watching violence does not mean that we will always be more aggressive or violent but it increases the chances. The way the violence is presented will have an impact on us too. For instance, if the violence is presented in a justifiable way, we can be led to aggressive behaviours. The central assumption of aggressive theory is that exposure to aggressive stimuli will increase physiological and emotional arousal, which will increase the probability of violence (Berkowitz, 1964). The social learning theory by Bandura suggests that viewing any content leads children and sometimes youth to reproduce this content when there is good reason to reproduce it in their environment (Dorr, 1986). Other authors have highlighted that media violence can lead to the process of desensitisation. Desensitisation refers to the gradual reduction in responsiveness to an arousaleliciting stimulus as a function of repeated exposure. In the context of media violence, desensitisation more specifically describes a process by which initial arousal responses to violent stimuli are reduced, thereby changing an individual's present internal state (Canagey, Anderson \& Bushman 2007). Desensitisation to violent media stimuli is thought to reduce anxious arousal. Fear is a spontaneous and probably innate response to human in reaction to violence. As with other emotional responses, repeated exposure to media violence can decrease negative effects (Anderson \& Dill, 2000). The conclusion is that exposure to media violence can create fear in audiences that is stable overtime. To gain better understanding of these complex issues, the researchers seek to:

1. Determine channels that denizens of Molyko, Buea, use to access information on the Anglophone crisis.

2. Examine the denizens' attitude after consuming violent reports on the Anglophone Crisis

\section{Materials ANd Methods}

This paper made use of a cross sectional survey design. A questionnaire was designed to collect data from 100 Molyko inhabitants. Molyko was chosen because it is a cosmopolitan area made up of students, workers, business operators and a host of others. It is the busiest community in Buea (a city which is the centre of the Cameroon Anglophone Crisis, due to its historical, socio-cultural and political importance in the English part of Cameroon). Purposive sampling technique was used to administer the questionnaires. This technique was chosen because the selection of respondents was based on two criteria. Firstly, they should be denizens of the area of study; secondly, they should be consumers of TV contents especially contents on the Anglophone crisis. The data was collected, cleaned and analysed using the Statistical Package for Social Scientists Software (SPSS) version 21. 
The analysis reveal that $48(50 \%)$ of the respondents were male and $48(50 \%)$ female giving a response rate of $96 \%$.

\section{RESULTS AND DISCUSSION}

Determine channels that denizens of Molyko used to access information about Anglophone crisis.

Table1. Respondents rating of Media outlets used to access violent contents of the Anglophone crisis

\begin{tabular}{|l|l|l|l|}
\hline \multirow{2}{*}{ Media } & \multicolumn{2}{|l|}{ Viewers ratings on media used to access violent content } & \\
\cline { 2 - 4 } & Used & Not-used & Total \\
\hline Equinox TV & $71(74 \%)$ & $25(26 \%)$ & $96(100 \%)$ \\
\hline Canal 2 English & $33(34.4 \%)$ & $63(65.6 \%)$ & $96(100 \%)$ \\
\hline CRTV & $11(11.5 \%)$ & $85(88.5 \%)$ & $96(100 \%)$ \\
\hline SCBC & $5(5.2 \%)$ & $91(94.8 \%)$ & $96(100 \%)$ \\
\hline WhatsApp & $37(38.5 \%)$ & $59(61.5 \%)$ & $96(100 \%)$ \\
\hline Facebook & $49(51 \%)$ & $47(49 \%)$ & $96(100 \%)$ \\
\hline Youtube & $22(22.9 \%)$ & $74(77.1 \%)$ & $96(100 \%)$ \\
\hline
\end{tabular}

Findings reveal that Molyko denizens mostly used Equinox TV 71 (74\%), Canal 2 English TV 33 (34.4\%) for mainstream television and Face book 49 (51\%), WhatsApp 37 (38.5\%) for social media platforms as channels to get updates about the Anglophone crisis. Respondents also use the Southern Cameroons Broadcasting Corporation (SCBC) - the separatists channel based in South Africa 5 (5.2\%), Cameroon Radio Television (CRTV) 11 (11.5\%) and YouTube 22 (22.9\%) to get updates about the Cameroon Anglophone crisis. Equinox Television, a private television station is known to be critical towards government activities and focuses on reporting what CRTV, the governmentowned audio-visual media downplays or fails to report. Owing to this, many Cameroonians have become fervent audiences of the medium as compared to CRTV which is considered by many to be a propaganda outlet for the government. On the other hand, SCBC is least watched owing to the fear of security forces ransacking homes and destroying TV sets (African Media Barometer: Cameroon, 2018; http://scbc.com.tag.crisis). Regarding YouTube, it is costly to watch videos online.

Examine Molyko denizens' attitude after consuming violent reports on the Cameroon Anglophone Crisis

Do violent reports of the crisis make you feel that Cameroon is full of violence?

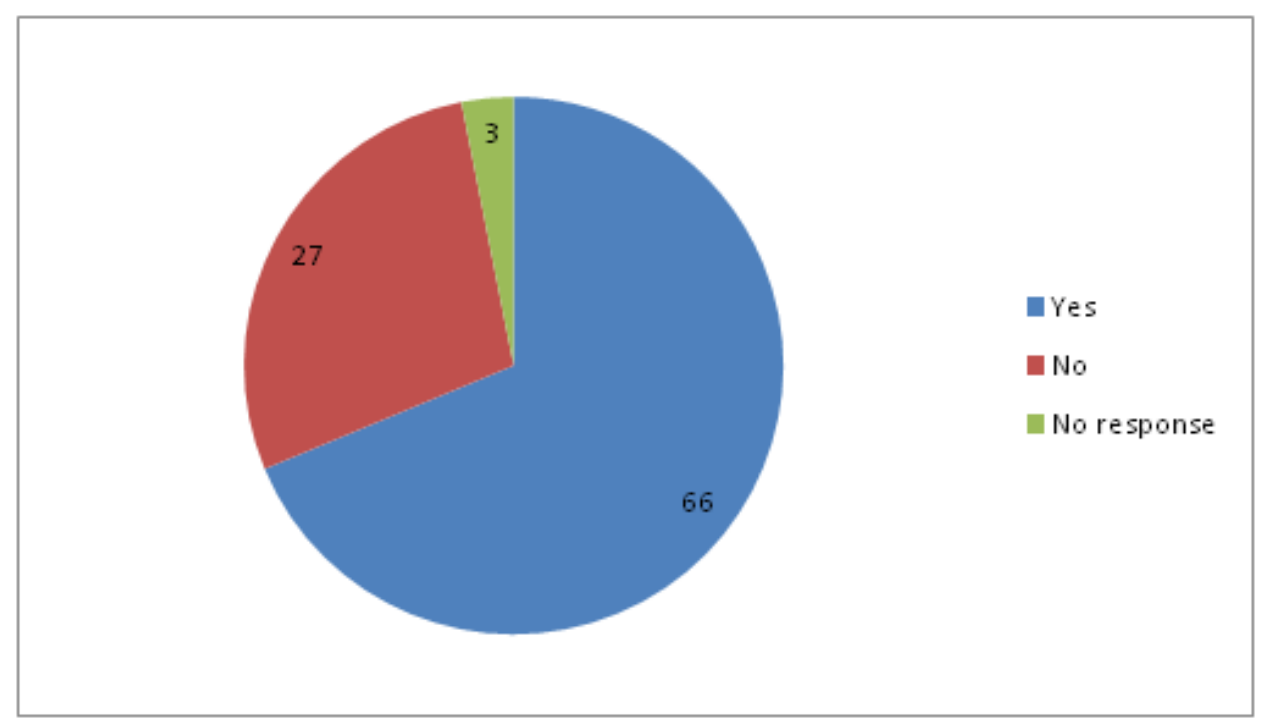

Fig1. Audience perception of reality after consuming violent contents

The analysis presented in fig 1 above shows that respondents have different interpretations of reality after the consumption of violent contents through multimedia. While $66(68.8 \%)$ respondents think Cameroon in particular and the world in general, are full of violence, 27 (28.1\%) of respondents do not think same. This analysis confirms that the effect of exposure to violent content over multimedia devices differ across media audience but support Gerbner, Gross, Jackson-Beeck, Jeffries-Fox, \& Signorielli, (1978) and Wilkinson \& Fletcher, (1995) view that too much negative portrayal of crime and violence in the media may cause media consumers to believe the world is a mean and harsh place. 
Results of Table 3 below bring out this difference according to audience reaction after the consumption of violent reports on the Cameroon Anglophone crisis.

Table3. Audience reaction after consuming violent reports on the Cameroon Anglophone Crisis

\begin{tabular}{|l|l|l|}
\hline Audience's reactions towards media violent & Frequency & Percentage \\
\hline Makes me to be reserved and cautious of my words & 38 & $39.6 \%$ \\
\hline Scared & 21 & $21.9 \%$ \\
\hline Develop hatred towards government & 14 & $14.6 \%$ \\
\hline Develop hatred towards the Separatists & 7 & $7.3 \%$ \\
\hline Feel like joining the armed struggle & 5 & $5.2 \%$ \\
\hline Develop hatred towards government and Separatists & 8 & $8.3 \%$ \\
\hline No response & 3 & $3.1 \%$ \\
\hline Total & $\mathbf{9 6}$ & $\mathbf{1 0 0}$ \\
\hline
\end{tabular}

Varied reactions characterise the respondents' reactions towards the exposure to multimedia violence on the Anglophone crisis. Out of 96 respondents, 38 (39.6\%) acknowledge that watching violentrelated content about the Anglophone crisis makes them to be reserved and cautious of what they say. $21(21.9 \%)$ further highlight that they become scared of eventualities and their surrounding, 14 $(14.6 \%)$ assert that they develop hatred towards the Cameroon government as a result of media reports while $7(7.3 \%)$ assert that they develop hatred towards the separatists. Just a few respondents 5 (5.2\%) acknowledge that media violence reports on the Anglophone crisis makes them to have the feeling of joining the separatists in the armed struggle against government security forces.

These findings actually reveal the effect of media violence exposure on viewers. Media reports on the Anglophone crisis have instilled mistrust, fear, anger and hatred in the minds of Cameroonians. These findings are supported by Tchoyi (2017) and Anderson et al. (2003). Anger and hatred are aggressive emotions which have consequences of aggressive behaviour (Anderson et al., 2003; Berkowitz, 1964). Also, emotions of fear and mistrust are eminent in the findings as most of the respondents $38(39.6 \%)$ have become reserved and cautious of their utterances and this has a negative effect on pro-social behaviour as asserted by Zeng, Dai, Tang, \& Zhang, (2004); Anderson \& Bushman, (2001); and Huesmann, Moise-Titus, Podolski, \& Eron (2003).

\section{CONCLUSION}

Violent reports of the Anglophone crisis in Cameroon have generated insecurity, mistrust, fear, anger and hatred among Molyko, Buea, dwellers. While some are traumatised and frightened due to exposure to violent messages, others are somewhat critical of the messages to the extent that they believe the reports are exaggerative. The power of the media should not be neglected especially during crisis periods and governments as well as media practitioners and other conflict stakeholders should be cautious of the effects of media messages on their audiences in creating, escalating and promoting crisis situations.

\section{REFERENCES}

[1] African Media Barometer: the first home grown analysis of the media landscape in Africa. Cameroon (2018). Friedrich-Ebert-Stiftung (FES), Namibia, Fesmedia Africa Windhoek.

[2] Anderson, C. \& Dill-Shackleford, K. (2000). Video Games and Aggressive Thoughts, Feelings, and Behavior in the Laboratory and in Life. Journal of personality and social psychology. 78. 772-90. 10.1037//0022-3514.78.4.772.

[3] Anderson, C. A., Berkowitz, L., Donnerstein, E. I., Huesmann, L. R., Johnson, J. D., Linz, D., ... Wartella, E. (2003). The Influence of Media Violence on Youth. Psychological Science in the Public Interest, 4(3), 81-110. https://doi.org/10.1111/j.1529-1006.2003.pspi_1433.x

[4] Anderson, C.A. and Bushman, B.J. (2001) Effects of violent video games on aggressive behaviour, aggressive cognition, aggressive affect, physiological arousal, and pro- social behaviour: A meta-analytic review of the scientific literature. Psychological Science, 5, 353-359. http://dx.doi.org/10.1111/14679280.00366

[5] Anderson, C.A., Lindsay J.J, \& Bushman B., (1999). Research in the psychological laboratory: Truth or triviality. Current Directions in psychogical science.1999; 8:3-9

[6] Ballard M.E and Lineberger, R (1997). Video Game Violence and Confederate Gender: Effects on Reward abd Punishment Given by College Males Cullingford:, children and television, Gower, Aldershot, 1984 p.180 today 
[7] Ballard, M. and R. Lineberger. Video Game Violence and Confederate Gender: Effects on Reward and Punishment given by college males. Sex Roles, 41, 541-558, 1999.

[8] Berkowitz, L (1964). Aggressive Cues in Aggressive Behaviour and Hostility Catharsis. Psychological Review, 71(2), 104 -122.http://dx.doi.org/10.1037/h0043520

[9] Berkowitz, L. (1965). Some aspects of observed aggression. Journal of Personality and Social Psychology, 2, 359-369.

[10] Berkowitz, L. (1993). Aggression: Its causes, consequences, and control. New York: McGraw-Hill.

[11] Berkowitz, L., \& Geen, R.G. (1967). Stimulus qualities of the target of aggression: A further study. Journal of Personality and Social Psychology, 5, 364-368

[12] Bushman, B. and Anderson, C. Violent Video Games and Hostile Expectations: A Test of the General Aggression Model. Personality and Social Psychology Bulletin. 28, 2002, 1679-1686.

[13] Bushman, B.J., \&Huesmann, L.R. (2001).Effects of televised violence on aggression. In D. Singer \& J. Singer (Eds.), Handbook of children and the media (pp. 223-254). Thousand Oaks, CA: Sage Publications.

[14] Crisis Group Africa Briefing N 130,19 October 2017. Cameroon:A Worsening Anglophone Crisis Calls for Strong Measures.

[15] Douglas A.G (2013).Catharsis and Media Violence: A Conceptual Analysis. 491-510 dio; $10.3390 / \operatorname{soc} 3040491$

[16] Carnagey, N. \& Anderson, C. \& Bushman, B. (2007). The Effect of Video Game Violence on Physiological Desensitization to Real Life Violence. Journal of Experimental Social Psychology. 43. 489496. 10.1016/j.jesp.2006.05.003.

[17] Chaffee, S.H. (1972).Television and adolescent aggressiveness (overview). In G.A. Comstock \& E.A. Rubinstein (Eds.), Television and social behaviour: A technical report to the Surgeon General's Scientific Advisory Committee on Television and Social Behavior: Vol. 3. Television and adolescent aggressiveness (DHEW Publication No. HSM 72-9058, pp. 1-34). Washington, DC: U.S. Government Printing Office

[18] Comstock, G. (1980). New emphases in research on the effects of television and film violence. In E.L. Palmer \& A. Dorr (Eds.), Children and the faces of television: Teaching, violence, selling (pp. 129-148). New York: Academic Press

[19] Dorr, A. (1986). Television and Children: A Special Medium for a special audience: Newbury Park, CA: Sage

[20] Eysenck, H.J., \& Nias, D.K.B. (1978).Sex, violence, and the media. New York: Saint Martin's Press

[21] Feshbach, S. (1984). The catharsis hypothesis, aggressive drive and the reduction of aggression. Agress. Bihav 1984, 10,91-101

[22] Florea, M. (2013).Media Violence and Cathartic Effect. Procedia-Social and Behavioural Sciences No 92 , P. $349-353$.

[23] Geen, R.G. (1990). Human aggression. Pacific Grove, CA: Brooks/Cole

[24] Geen, R.G. (2001). Human aggression (2nd ed.). Philadelphia: Open University Press

[25] Geen, R.G., \& Thomas, S.L. (1986).The immediate effects of media violence on behaviour. Journal of Social Issues, 42(3), 7-27.

[26] Gerbner, G \& Gross, L. (1976). Living with Television: The violence profile. Journal of communication, 26(2) 172-199

[27] Gerbner, G., \& Gross, L (1976). The scary world of TV's heavy viewer. Psychology Today, 10(4), 41-89

[28] Gerbner, G., Gross, L., Morgan, M., Signorielli, N., \& Jackson -Beeck, M.( 1979). The Demonstration of power: Violence Profile. Journal of communication 29(10), 177-196

[29] Glassner, B. (1999). The culture of fear: Why Americans are afraid of the wrong things. New York, NY, US: Basic Books.

[30] Gross, L.Signorielli, N. and Morgan, M. Aging with Television: Images on Television Drama and Conceptions of Social Reality. Journal of Communication, 1980b, 30(1).37.47.

[31] Gross, L., Jackson-Beeck, M., Jeffries-Fox, S., \&Signorielli, N. (1978). Cultural indicators: Violence profile, no. 9. Journal of Communication, 28, 176-207.

[32] Huesmann, L.R., \& Guerra, N.G. (1997). Children's normative beliefs about aggression and aggressive behavior. Journal of Personality and Social Psychology, 72, 408-419

[33] Huesmann, L.R., \& Miller, L.S. (1994).Long-term effects of repeated exposure to media violence in childhood. In L.R. Huesmann (Ed.), Aggressive behaviour: Current perspectives (pp. 153-183). New York: Plenum Press

[34] Huesmann, L.R., Moise, J.F., \& Podolski, C.L. (1997).The effects of media violence on the development of antisocial behavior. In D.M. Stoff, J. Breiling, \& J.D. Maser (Eds.), Handbook of antisocial behaviour (pp. 181-193). New York: John Wiley \& Sons 
[35] Huesmann, L.R., Moise-Titus, J., Podolski, C. and Eron, L.D. (2003) Longitudinal relations between children's exposure to TV violence and their aggressive and violent behaviour in young adulthood: 19771992. Developmental Psychology, 39, 201-221. http://dx.doi.org/10.1037/0012-1649.39.2.201.

[36] Konings, P. \& Nyamnjoh, F. (1997). The Anglophone Problem in Cameroon. The Journal of Modern African Studies, 35(2), 207-229.

[37] Lefkowitz, M. M. \& Huesmann, L. R. (1980). Concomitants of television violence viewing in children. In E L. Palmer \& A. Dorr (Eds.), Children and the faces of television Teaching, violence, selling (pp. 165182). New York: Academic Press

[38] Lekeaka, A.N. (2017). The Effects of Violent TV Programs on Child Development (Unpublished)

[39] Miller, K. (2005). Communication theorist: perspectives, processes, and context. New York: McGrawHill.

[40] Ogunwole, O.A. (2014). A Conceptual Analysis of Cultivation Theory. PG/14/0024

[41] Okereke, C. N. (2018). Analysing Cameroon's Anglophone Crisis. Counter Terrorist Trends and Analyses, 10(3). Pp 8-12. https://www.jstor.org/stable/10.2307/26380430

[42] Paik, H., \& Comstock, G. (1994). The effects of television violence on antisocial behaviour: A metaanalysis. Communication Research, 21, 516-546.

[43] Puachant, T. C. \& Mitroff I. (1992). Transforming the crisis- Prone Organization. San Francisco: CA :Jossey- Bass Publisher.

[44] Rule, B.G., \& Ferguson, T.J. (1986). The effects of media violence on attitudes, emotions, and cognitions. Journal of Social Issues, 42(3), 29-50.

[45] Tala, K. I. \& Ngange, K. L. (2019). Anglophone lawyers and teachers strikes in Cameroon (2016 - 2017): A multidimensional perspective. Yaoundé, Les Presses Universitaires de Yaoundé.

[46] Tchoyi, A. (2017, January 18). Anglophone Marginalisation: Cold Hard Facts. The Rambler, edition No. 0037.

[47] Wilkinson, J. S., \& Fletcher, J. E. (1995). Bloody news and vulnerable populations: An ethical question. Journal of Mass Media Ethics, 10:3, 167.

[48] Zeng, F.L., Dai, Q.Y., Tang, S.Q. and Zhang, W.Y. (2004) Effect of watching violent TV on aggressive behavior of adolescents. Chinese Journal of Clinical Psychology, 1, 35-37.

[49] Zhang, Q., Xiong, D. and Tian, J. (2013) Impact of media violence on aggressive attitude for adolescents. Health, 5, 2156-2161. doi: 10.4236/health.2013.512294.

Citation: Kingsley Lyonga Ngange, et al. "Media Violence Reports on the Cameroon Anglophone Crisis: Implication on Buea Denizens ". International Journal of Media, Journalism and Mass Communications (IJMJMC), vol 6, no. 1, 2020, pp. 21-27 doi: http://dx.doi.org/10.20431/2454-9479.0601003

Copyright: (c) 2020 Authors. This is an open-access article distributed under the terms of the Creative Commons Attribution License, which permits unrestricted use, distribution, and reproduction in any medium, provided the original author and source are credited. 